\title{
Preclinical Efficacy and Safety of the Novel Antidiabetic, Antiobesity MetAP2 Inhibitor ZGN-1061
}

\author{
Bryan F. Burkey, Niel C. Hoglen, Philip Inskeep, Margaret Wyman, Thomas E. Hughes, \\ and James E. Vath
}

Zafgen, Inc., Boston, Massachusetts (B.F.B., N.C.H., M.W., T.E.H., J.E.V.) and InskeepDMPK, LLC (P.I.), East Lyme, Connecticut

Received November 11, 2017; accepted February 23, 2018

\begin{abstract}
Methionine aminopeptidase 2 (MetAP2) inhibition is a promising approach to treating diabetes, obesity, and associated metabolic disorders. Beloranib, a MetAP2 inhibitor previously investigated for treatment of Prader-Willi syndrome, was associated with venous thrombotic adverse events likely resulting from drug effects on vascular endothelial cells (ECs). Here, we report the pharmacological characterization of ZGN-1061, a novel MetAP2 inhibitor being investigated for treatment of diabetes and obesity. Four weeks of subcutaneous administration of ZGN-1061 to diet-induced obese (DIO) insulin-resistant mice produced a $25 \%$ reduction in body weight, primarily due to reduced fat mass, that was comparable to beloranib. ZGN-1061 also produced improvements in metabolic parameters, including plasma glucose and insulin, and, in HepG2 cells, initiated gene changes similar to beloranib that support observed in vivo
\end{abstract}

pharmacodynamics. In vitro studies in ECs demonstrated that ZGN-1061 effects on EC proliferation and coagulation proteins were greatly attenuated, or absent, relative to beloranib, due to lower intracellular drug concentrations, shorter half-life of inhibitor-bound MetAP2 complex, and reduced cellular enzyme inhibition. In dogs, ZGN-1061 was more rapidly absorbed and cleared, with a shorter half-life than beloranib. Unlike beloranib, ZGN-1061 did not increase coagulation markers in dogs, and ZGN-1061 had a greatly improved safety profile in rats relative to beloranib. In conclusion, ZGN-1061 and beloranib demonstrated similar efficacy in a mouse model of obesity, while ZGN-1061 had a markedly improved safety profile in multiple in vitro and in vivo models. The lower duration of exposure characteristic of ZGN-1061 is expected to provide a meaningfully enhanced clinical safety profile.

\section{Introduction}

Methionine aminopeptidase 2 (MetAP2) inhibitors are a novel class of drugs being investigated for the treatment of diabetes, obesity, and metabolic disease. MetAP2 is an enzyme responsible for the cotranslational cleavage of $\mathrm{N}$-terminal methionine from a subset of newly made proteins important for a broad range of cellular function, including metabolism, growth, and proliferation (Warder et al., 2008). MetAP2 is also known to bind other important regulatory proteins such as extracellular signal-regulated kinase 1/2 (ERK 1/2) and elongation initiation factor $2 \alpha$ (EIF2 $\alpha$ ) (Datta et al., 2004). Most MetAP2 inhibitors are structurally related to the natural product fumagillin, a small molecule that covalently binds to His-231 in the catalytic active site of the enzyme, rendering it unable to cleave the N-terminal methionine of substrate proteins (Sin et al., 1997). MetAP2

This study was funded by Zafgen, Inc.

http://doi.org/10.1124/jpet.117.246272. inhibitors are unique in that they produce marked reductions in body fat and improvements in glycemic control through a mechanism that impacts fat metabolism, fatty acid synthesis, and fat storage (Brakenhielm et al., 2004; Kim et al., 2007; Lijnen et al., 2010; Elfers and Roth, 2017). The MetAP2 inhibitor beloranib (also referred to as ZGN-440) has produced consistent and clinically meaningful weight loss in clinical trials of patients with obesity, type 2 diabetes, Prader-Willi syndrome (PWS), and hypothalamic injury-associated obesity (Hughes et al., 2013; Kim et al., 2015; Proietto et al., 2016; McCandless et al., 2017; Shoemaker et al., 2017). In patients with type 2 diabetes, beloranib produced $13 \%$ weight loss and a $2.0 \%$ reduction in $\mathrm{HbA} 1 \mathrm{c}$ over 26 weeks of treatment (Proietto et al., 2016).

Beloranib was generally well tolerated in preclinical testing. However, in clinical trials of beloranib in patients with obesity, PWS, or type 2 diabetes, adverse events (AEs) of venous thromboembolism occurred in beloranib-treated patients (McCandless et al., 2017) despite being otherwise generally well tolerated. These AEs included superficial

ABBREVIATIONS: $\mathrm{AE}$, adverse event; $\mathrm{AUC}_{0-t}$, area under the curve from time 0 to the last measurable timepoint; beloranib, 3-[4-(2dimethylaminoethoxy)phenyl]-acrylic acid 5-methoxy- 4-[2-methyl-3-(3-methyl-but-2-enyl)-oxiranyl]-1-oxa-spiro[2,5]oct-6-yl ester; DIO, dietinduced obese; DMSO, dimethylsulfoxide; DXA, dual-energy X-ray absorptiometry; EC, endothelial cell; HUVEC, human umbilical vein endothelial cell; IAM, iodoacetamide; LC-MS/MS, liquid chromatography and tandem mass spectrometry; MetAP2, methionine aminopeptidase 2; NOAEL, no observed adverse effect level; PAI-1, plasminogen activator inhibitor-1; PK, pharmacokinetic; PWS, Prader-Willi syndrome; RPKM, reads per kilobase per million mapped reads; THX 1-6, thioredoxin protein n-terminal residues 1-6; TM, thrombomodulin; vWF, von Willebrand factor; ZGN1061, (3R,4S,5S,6R)-5-methoxy-4-[(2R,3R)-2-methyl-3-(3-methylbut-2-en-1-yl)oxiran-2-yl]-1-oxaspiro[2.5]octan-6-yl 3-[2-(morpholin-4-yl)ethyl]azetidine-1-carboxylate. 
thrombophlebitis, deep vein thrombosis, and pulmonary embolism, including two fatal pulmonary emboli in patients with PWS that resulted in cessation of beloranib development.

After the AEs of venous thromboembolism occurred in clinical trials of beloranib, our investigation focused on determining the mechanism for these effects. This investigation evaluated direct effects of beloranib exposure in vitro and in vivo on coagulation factor function, blood clot formation and lysis, platelet function, neutrophil function, and vascular endothelial cell (EC) function. In ECs, the natural product fumagillin, a prototype inhibitor of MetAP2 (Sin et al., 1997), could serve to alter the homeostatic balance of ECs by inhibiting EC proliferation through blocking the cell cycle at the G1 phase (Kusaka et al., 1991). It has been shown that MetAP2 inhibition directly causes activation of p53 in ECs, which in turn upregulates p21, leading to cell cycle arrest and a procoagulable state (Zhang et al., 2000). Previous studies in human umbilical vein endothelial cells (HUVECs) have shown that increases in p21 expression promote a prothrombotic response in these cells (Kumar et al., 2011). Inhibition of EC proliferation, which is observed following prolonged exposure to MetAP2 inhibitors, may lead to an altered repair response to EC injury, serving to promote clot initiation and/or propagation. We hypothesized that the extended EC exposure to a MetAP2 inhibitor initiates an intracellular signaling cascade known to promote coagulation (Yau et al., 2015), resulting in the safety limitations observed in clinical trials of beloranib.

ZGN-1061 is a novel, potent, selective, and covalent inhibitor of the MetAP2 enzyme that was developed to minimize EC exposure and have an improved safety profile compared with beloranib, while retaining similar metabolic efficacy in models of obesity and cardiometabolic disease. Here, we report the key in vitro and in vivo pharmacodynamic and pharmacokinetic (PK) studies conducted to compare the safety and efficacy of ZGN-1061 with beloranib and identify crucial differences between the two compounds on factors related to coagulation and drug safety.

\section{Materials and Methods}

Animal experiments were performed in accordance with the Guide for the Care and Use of Laboratory Animals as adopted and promulgated by the US National Institutes of Health or local equivalent and were approved by the Institution's Animal Care and Use Committee or local equivalent. Unless described otherwise, animals (mouse, rat, and dog studies) were maintained under standard conditions (12-hour light/dark cycle and approximately $21 \pm 4^{\circ} \mathrm{C}$ and $55 \% \pm 15 \%$ relative humidity), and food [rodent pellet chow (Research Diets, Brunswick NJ) or similar] or canine pellet (Certified Dog Diet 2021C; Harlan Teklad Diets, Madison, WI) or canned (i.e., Cesar Mars Petcare, Victoria, Australia) and water were available ad libitum. ZGN-1061 or beloranib (ZGN-440) were supplied by Zafgen, Inc. ZGN-1061 and beloranib structures are shown in Fig. 1. Unless described otherwise, drugs were administered subcutaneously daily (efficacy studies) or every 3 days (safety studies). ZGN-1061 vehicle was $5 \%$ mannitol in water ( $5 \%$ mannitol in $10 \mathrm{mM}$ sodium phosphate, $\mathrm{pH}$ 7.5). Beloranib vehicle was $0.0416 \%$ sodium carboxymethyl cellulose, $0.0001 \%$ Poloxamer 188, and $0.1664 \%$ mannitol in $9.365 \mathrm{mM}$ Sorenson buffer, $\mathrm{pH}$ 7.4. The solubility of ZGN-1061 in water at $\mathrm{pH} 7.0$ is $96 \mathrm{mg} / \mathrm{ml}$ compared with beloranib's aqueous solubility at $\mathrm{pH} 7.1$ of $0.3 \mathrm{mg} / \mathrm{ml}$.

Effects of ZGN-1061 and Beloranib on Body Weight and Glycemic Markers in High-Fat Diet-Induced Obese Mice. Male

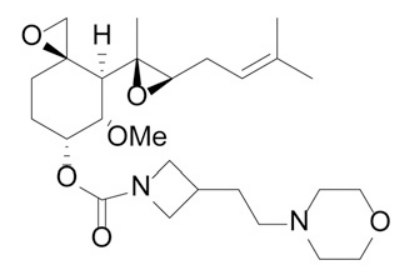

ZGN-1061

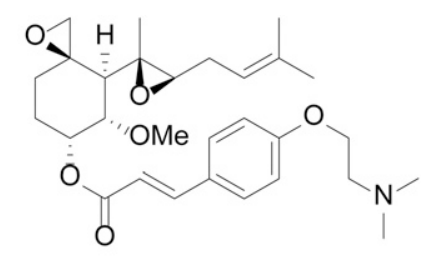

Beloranib
Fig. 1. Chemical structures of ZGN-1061 and beloranib.

C57BL/6J mice (Charles River UK, Margate, UK) 7 to 8 weeks of age were housed at the testing facility (RenaSci Ltd., Nottingham, UK). Food (high-fat diet: D12451 diet, $45 \%$ kcal as fat; Research Diets) was available ad libitum. Animals were group housed for 24 weeks and weighed weekly, after which animals were singly housed and placed on a reverse-phase light/dark cycle (lights off from 0930 to 1700). After 37 weeks of exposure to high-fat diet ( 2 weeks prior to drug treatment), animals were weighed and handled daily to mimic study procedures. All animals received vehicle subcutaneously daily in the morning for 1 week prior to drug treatment.

Animals ( $n=10$ /group) were allocated to treatment groups $[0.3 \mathrm{mg} /$ $\mathrm{kg}$ ZGN-1061, $0.1 \mathrm{mg} / \mathrm{kg}$ beloranib, or vehicle (10 mM phosphate in 5\% mannitol, $\mathrm{pH}$ 7.2)] to achieve similar baseline characteristics based on body weight, food and water intake, and fasting glucose and insulin at baseline. The selected doses of ZGN-1061 and beloranib are the maximally effective doses for reductions of body weight in DIO mice. During the treatment phase, animals were dosed subcutaneously daily; body weight and food and water intake were recorded daily. Food was measured in the morning at the time of dosing. All food was removed from the hopper of the cage lid and transferred to a container prior to weighing on a balance. Care was taken to ensure all food was collected, including any food fragments on the cage floor. The food was then returned to the hopper and the cage lid replaced. Blood samples were obtained from fasted animals on day 29 of the study. Blood was taken from a living animal by small section of the lateral tail vein during brief restraint. Blood flow was facilitated by gentle palpation/stroking of the tail and was collected into tubes by capillary action. Prior to blood sampling procedures, mice were briefly exposed $\left(\sim 2\right.$ minutes) to a purpose built warming chamber of $38^{\circ} \mathrm{C}$. All blood samples (approximately $30 \mu \mathrm{l}$ ) were taken into lithium heparin-coated tubes (Sarstedt CB300LH), and plasma samples were stored frozen $\left(-80^{\circ} \mathrm{C}\right)$ until determination of plasma glucose and insulin.

At baseline and immediately after dosing on days 15 and 26, dualenergy X-ray absorptiometry (DXA) readings were taken using a Lunar PIXImus II Densitometer on mice anesthetized with isoflurane. Analysis of the mice was with a defined region of interest to exclude the head. Energy intake was calculated as the mean daily energy intake normalized to lean mass. Week 2 energy intake was calculated as the mean daily energy intake on days 14 to 16 normalized to lean mass (gram) DXA measurements on day 15 . Week 4 energy intake was calculated as the mean daily energy intake on days 25-27 normalized to lean mass (gram) DXA measurements on day 26 .

Homeostatic model assessment for insulin resistance (HOMA-IR) was calculated using insulin and glucose data on day 29 using the equation (insulin $\mathrm{ng} / \mathrm{ml} \times$ glucose $\mathrm{mM}) /(22.5 \times 0.0455)$. Lipids and biomarkers were collected in the morning after an overnight fast (16 hours) at endpoint only.

Tissue N-terminal of thioredoxin (THX 1-6, MVKLIE) was measured by homogenizing tissue $1: 3(\mathrm{w} / \mathrm{v})$ in tissue protein extraction reagent (Thermo Fisher Scientific, Waltham, MA). The homogenized samples were centrifuged at $10,000 \mathrm{rpm}$ for 10 minutes, and supernatant was transferred to another tube. The total protein concentration of the supernatant was measured by bicinchoninic acid assay. The

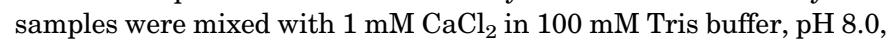
and then reduced with Tris(2-carboxyethyl) phosphine at room 
temperature for 10 minutes. The samples were denatured at $100^{\circ} \mathrm{C}$ for 10 minutes and cooled to room temperature. The samples were mixed with iodoacetamide (IAM) and alkylated at $300 \mathrm{rpm}$ on the incubation shaker for 30 minutes in the dark. Dithiothreitol was added to react with excess IAM at room temperature for 10 minutes. Samples were mixed (25:1, protein/enzyme) with endoproteinase Glu-C solution and digested overnight $(16 \mathrm{~h})$ at $37^{\circ} \mathrm{C}$. The reaction was quenched by adding $10 \%$ formic acid. After digestion, the samples were centrifuged at $10,000 \mathrm{rpm}$ for 10 minutes and supernatant $(20 \mu \mathrm{l})$ was transferred to a new sample plate and mixed with $10 \mu \mathrm{l}$ of $0.1 \%$ formic acid in 90/10 water/acetonitrile (v/v). Sample was spiked with internal standard then subjected to liquid chromatography and tandem mass spectrometry (LC-MS/MS) with an API Sciex TripleTOF 6600 mass spectrometer. Concentrations of THX 1-6 were expressed as nanograms per milligram total protein.

Effects of ZGN-1061 and Beloranib on HepG2 Cell Gene Expression. HepG2 cells were seeded in $3 \mathrm{ml}$ of minimum essential media at $6 \times 105$ cells/well of a six-well plate. Cells were cultured 24 hours. Fresh culture media was replaced containing dimethylsulfoxide (DMSO) vehicle alone at a final concentration of $0.1 \%$ or with ZGN-1061 or beloranib at a final concentration of $6 \mathrm{nM}$. Cells were cultured a further 2 or 24 hours, after which culture media was removed and cells were washed once with ice-cold phosphate-buffered saline. Cells were lysed for isolation of RNA using $1 \mathrm{ml}$ of Tri-reagent (Molecular Research Center, Cincinnati, $\mathrm{OH}$ ) per well and sufficient pipetting up and down to fully lyse cells. Lysates were frozen and stored at $-80^{\circ} \mathrm{C}$ until further processing. Total RNA was isolated from the samples using the TRI Reagent method and digested with RNase free DNase I (Epicentre, Middleton, WI) and repurified using Agencourt RNAClean XP beads (Beckman Coulter Life Sciences, Indianapolis, IN). Amplified cDNA libraries suitable for sequencing were prepared from $500 \mathrm{ng}$ of DNA-free total RNA. Sequencing was performed using an llumina NextSEq 500 according to methods established by Ocean Ridge Biosciences (Deerfield Beach, FL). Realtime image analysis and base calling were performed on the instrument using the Real-Time Analysis software version 2.4.11. The reads per kilobase per million mapped reads ( $R P K M)$ values were filtered to retain a list of genes with a minimum of approximately 50 mapped reads in $25 \%$ or more samples. The threshold of 50 mapped reads is considered the reliable quantification threshold, because the RPKM values for a gene represented by 50 reads should be reproducible in technical replicates.

Effects of ZGN-1061 and Beloranib in HUVECs and HepG2 Cells. In vitro studies of ZGN-1061 and beloranib were conducted in cultured HUVECs (Lonza, Amboise, France). Cells were cultured in endothelial growth medium 2 cell culture media (Lonza), passaged by seeding at $3 \times 10^{3}$ cells $/ \mathrm{ml}$ on T175 flasks, and allowed to reach approximately $80 \%$ confluence before experiments were conducted. Cells were trypsinized and counted using trypan blue exclusion method using an automated Cedex cell counter. HepG2 cells (American Type Culture Collection, Manassas, VA) were seeded at $3 \times$ 103 cells $/ \mathrm{ml}$ in T150 flasks and grown to $60 \%$ confluence. Cells were exposed to ZGN-1061 or beloranib at $10 \mathrm{nM}$ final concentration for 1 hour, then washed to remove compound, and then cultured for different times until collection for MetAP2 analysis.

For LC-MS/MS experiments, cells were plated at $3 \times 10^{4}$ cells $/ \mathrm{ml}$ on tissue culture-treated T175 flasks at $35 \mathrm{ml} / \mathrm{flask}$ in triplicate and allowed to equilibrate overnight in a $\mathrm{CO}_{2}$ incubator. On the day of the experiment, cell culture medium was removed and fresh medium was added along with drug or vehicle. ZGN-1061 and beloranib were diluted in DMSO to yield stock concentrations of $10 \mu \mathrm{M}$. Subsequent dilutions were made in endothelial growth medium 2 cell culture media to yield a final DMSO concentration of $0.1 \%$ for cell incubations.

For LC-MS/MS sample preparation, cell culture media was removed, cells were washed with $10 \mathrm{ml}$ of Dulbecco's phosphate-buffered saline, and $500 \mu \mathrm{l}$ of tissue protein extraction reagent lysis buffer was added. Cell lysates were stored at $-80^{\circ} \mathrm{C}$. For EC proliferation experiments, cells were plated at $0.3 \times 10^{5}$ cells $/ \mathrm{ml}$ in a Corning
354649 96-well collagen-coated black microplate and allowed to equilibrate overnight in a $\mathrm{CO}_{2}$ incubator. After incubation with drug or vehicle, EC proliferation was analyzed using a DNA dye (CyQUANT) added to lysed cells to provide a fluorescent signal relative to the amount of DNA, allowing a measure of cell density. For assays measuring the cell cycle proteins p21 and p53, the coagulation markers thrombomodulin (TM), plasminogen activator inhibitor-1 (PAI-1), and von Willebrand factor (vWF), cultured HUVECs were incubated with drug or vehicle for 4,8 , or 72 hours prior to compound washout and assessment of cell protein concentrations. For the 4- and 8-hour incubations, cells were maintained by standard culture for the remainder of the 72-hour incubation period. Cell cycle protein levels were assessed using enzyme-linked immunosorbent assays.

For analysis of drug binding to the MetAP2 enzyme active site, HUVEC lysates were denatured, reduced, and alkylated with IAM, then treated with chymotrypsin to generate the MetAP2 peptide (amino acids 312-320) EVEIDGKTY and either the ZGN 1061-bound MetAP2 peptide $\mathrm{NNC}^{[\mathrm{CAM}]} \mathrm{AAH}^{[\mathrm{ZGN}-1061]} \mathrm{Y}$ or the beloranib-bound MetAP2 peptide $\mathrm{NNC}^{[\mathrm{CAM}]} \mathrm{AAH}^{[\text {beloranib] }} \mathrm{Y}$. Concentrations of the MetAP2-, ZGN-1061-, or beloranib-bound peptides were measured by LC-MS/MS. Measured peptide concentrations (in nanograms per milliliter) were converted to MetAP2-bound, ZGN-1061-bound, and beloranib-bound protein concentrations (nanograms per milligram total protein) in HUVEC lysates.

For analysis of MetAP2 enzymatic inhibitory activity of compounds in cells, the intact $\mathrm{N}$ terminus of the MetAP2 substrate protein thioredoxin-1 (THX 1-6) was quantified. HUVEC lysates were denatured, reduced, and treated with endoproteinase Glu-C to generate the N-terminal methionine THX 1-6 peptide, MVKQIE. Concentrations of MVKQIE were measured by LC-MS/MS. Measured peptide concentrations in nanograms per milliliter were converted to $\mathrm{N}$-terminal methionylated THX 1-6 protein concentrations (nanograms per milligram total protein) in HUVEC lysate.

PK Studies of ZGN-1061 and Beloranib in Dogs. PK characterization of ZGN-1061 and beloranib following acute administration was conducted in beagle dogs. Male and female beagle dogs of 9-11 months of age (ZGN-1061 study: Marshall BioResources, North Rose, NY; beloranib study: Beijing Marshall, Beijing, China) were individually housed at the testing facility (ZGN-1061 study: BASi, Mt. Vernon, IN; beloranib study: Korea Institute of Toxicology, Daejeon, South Korea). Approximately $325 \mathrm{~g}$ of pelleted food was provided daily.

Dogs received ZGN-1061 $0.6 \mathrm{mg} / \mathrm{kg}$ s.c. $(n=5$ males and 5 females $/$ group). In a separate study, dogs received beloranib $0.6 \mathrm{mg} / \mathrm{kg}$ s.c. $(n=$ 4 males and 4 females/group). Animals were observed twice daily for signs of ill health, morbidity, mortality, injury, and viability, and detailed clinical observations were conducted daily (including urine/ fecal examination and hands-on examination). Food was weighed daily, and body weights were recorded at least weekly.

Whole venous blood samples of approximately $1.0 \mathrm{ml}$ were collected from the jugular vein of animals on day 1 at $0.25,0.5,1,2,4$, and 8 hours after dosing (ZGN-1061) or day 1 at $0.5,1,2,4,8,24$, and 72 hours after dosing (beloranib). Samples were collected in tubes containing lithium heparin and processed for plasma by centrifugation (10 minutes at $3000 \mathrm{rpm}$ ). Supernatant was removed and stored frozen $\left(-70^{\circ} \mathrm{C}\right)$ until processed (BASi, West Lafayette, IN). Plasma drug concentration data were used to calculate PK parameters for individual concentration data using noncompartmental PK methods in Watson version 7.3.0.01 (Thermo Fisher Scientific, Inc.). The lower limit of quantification in dog plasma was $0.05 \mathrm{ng} / \mathrm{ml}$ for beloranib and $0.5 \mathrm{ng} / \mathrm{ml}$ for ZGN-1061.

Effect of ZGN-1061 and Beloranib on Coagulation Markers in Dogs. Male beagle dogs 10-20 months of age (Marshall BioResources) were individually housed at the testing facility (BASi) as described above. Dogs ( $n=6$ /group) received $2 \mathrm{mg} / \mathrm{kg}$ ZGN-1061 s.c. every 3 days on days $1,4,7$, and 10 . In a separate study, dogs $(n=6$ / group) received $0.6 \mathrm{mg} / \mathrm{kg}$ beloranib s.c. every 3 days for a total of eight planned doses (days 1, 4, 7, 10, 13, 16, 19, and 22). Animals 
were observed twice daily for signs of ill health, morbidity, mortality, injury, and viability; and daily detailed clinical observations were conducted (including urine/fecal examination and hands-on examination). Body weight and food intake were recorded daily. Blood was collected before each dose and 4 hours after each dose for hematology (e.g., platelet count), coagulation parameters (e.g., thrombin time, antithrombin III), and protein panel analysis (e.g., D-dimer) (Nextcea, Woburn, MA).

Toxicology Studies with ZGN-1061 and Beloranib in the Rat. Male and female Sprague-Dawley rats 9 to 10 weeks of age (Envigo RMS, Inc., Indianapolis, IN or Orient Bio Inc., Gyeonggi-do, South Korea) were individually housed at the testing facility (ZGN1061 study: BASi; beloranib study: Korea Institute of Toxicology). Rats ( $n=15 /$ group) received ZGN-1061 (2, 6, $25 \mathrm{mg} / \mathrm{kg}$, or vehicle) every 3 days for 28 days. In a separate study, rats $(n=20$ group) received beloranib $(0.2,0.6,2$, and $6 \mathrm{mg} / \mathrm{kg}$, or vehicle $(0.1 \%$ Tween 80/5\% D-mannitol solution) every 3 days for 28 days. Animals were allocated to treatment groups based on body weight, and body weight and food consumption were recorded weekly. In addition, animals were observed for clinical signs of toxicity, changes in body weight, as well as hematology, coagulation, and clinical chemistry parameters as described above. At necropsy, macroscopic pathologic findings were recorded, sperm motility and morphology were determined, selected organs were weighed, and selected tissues were collected for microscopic examination.

Statistical Analysis. Body weight and body weight gains (gram) were analyzed by analysis of covariance with day 1 body weight as a covariate. Food intake (kilojoule) was analyzed by analysis of covariance with average daily food intake during the baseline phase (days -6 to 0 ) as a covariate. DXA parameters were analyzed using a general linear model with treatment as a factor and baseline body weight and the same DXA parameter during the baseline DXA as covariates. Insulin data were log transformed prior to analysis. Glucose and insulin were analyzed by robust regression with treatment as a factor and day 1 body weight, the same parameter from the baseline, and animal bleeding order as covariates. Plasma lipids were analyzed by robust regression while biomarkers were analyzed by a general linear model following a log transformation; treatment and cohort were used as factors and baseline body weight and animal bleeding order as covariates. Cell pharmacology studies were analyzed in Excel, where indicated statistical analysis was performed using a Student's $t$ test. For dog coagulation markers, two-way analysis of variance was performed for effect of treatment and time, with Tukey's multiple comparison versus vehicle for study day. RNAseq gene expression data were analyzed by Ocean Ridge Biosciences by applying a one-way analysis of variance on RPKM data for the factors of treatment with a Tukey's honestly significant difference post hoc test to identify significant differences among the individual treatment groups relative to vehicle controls at the same time. The Tukey test generated $P$ values for all possible binary comparisons among treatment groups and then adjusted the $P$ values upward based on the total number of binary comparisons considered, which equaled $(n / 2 * n-1)$, where $n$ was the number of groups. Fold changes were also calculated for the same comparisons as the Tukey tests using the mean of each group being compared. All statistical analysis was performed using $\mathrm{R}$ version 3.2.2 statistical computing software.

\section{Results}

Effects of ZGN-1061 and Beloranib on Body Weight and Glycemic Markers in DIO Mice. At baseline, DIO mice exhibited elevated body weight compared with adult 20-week-old male C57BL/6J mice fed a standard chow (mean baseline body weight 48.0 vs. $31.3 \mathrm{~g}$ for DIO vs. chow fed, respectively). As well, fasting glucose ( $13.0 \mathrm{mM}$ for DIO vs. $10.8 \mathrm{mM}$ for chow) and insulin $(2.9 \mathrm{ng} / \mathrm{ml}$ for DIO vs. $0.5 \mathrm{ng} / \mathrm{ml}$ for chow) were significantly elevated in DIO mice, both
$P<0.001$. During treatment with maximally effective weight loss doses of ZGN-1061 and beloranib, body weight declined steadily, whereas body weight in the vehicle group increased
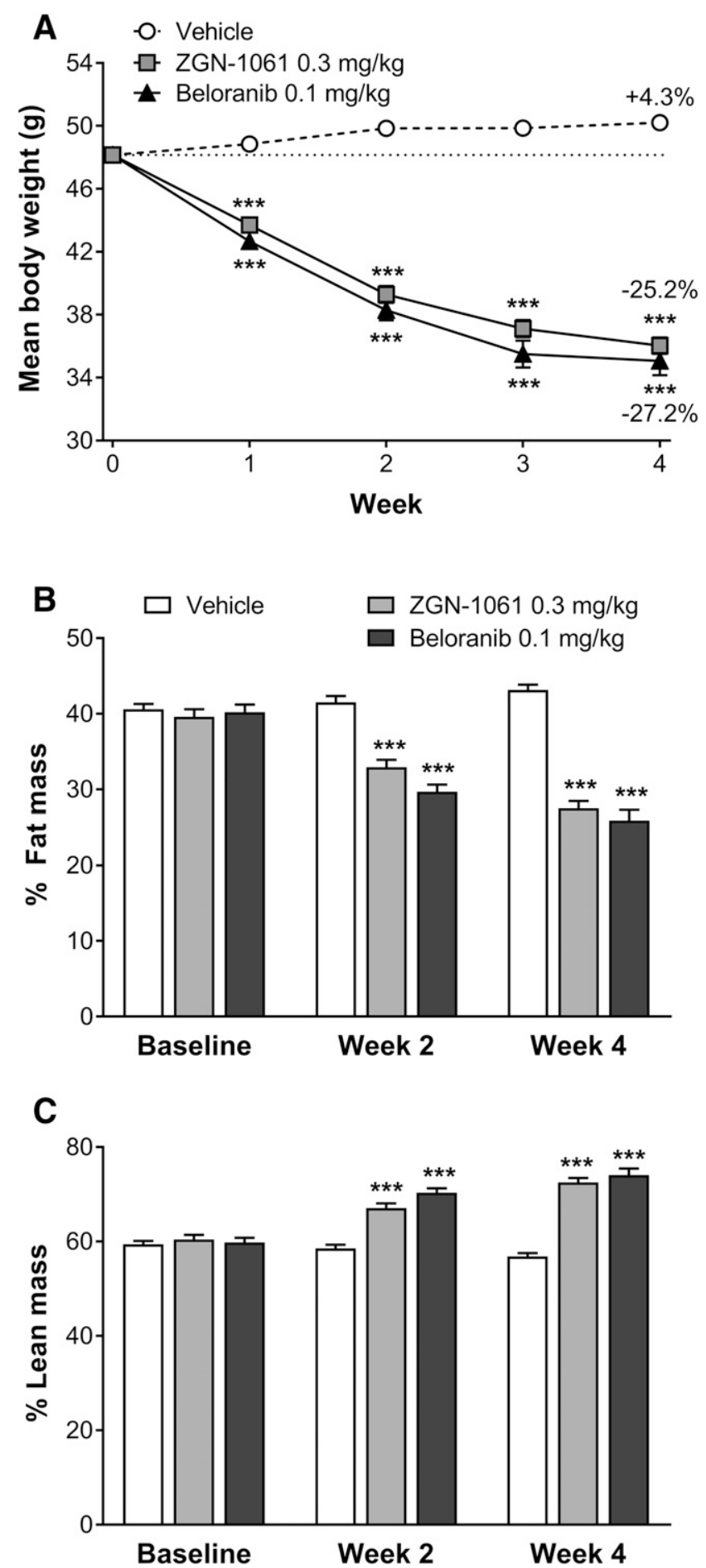

Fig. 2. Mice ( $n=10$ /group) received drug or vehicle subcutaneous daily for 28 days. (A) Mean and S.E.M. absolute change from baseline in body weight. (B) Mean and S.E.M. percentage body fat mass. (C) Mean and S.E. M. percentage lean mass. Body weight and overall and weekly body weight gains (gram) were analyzed by analysis of covariance with day 1 body weight as a covariate. DXA parameters were analyzed using a general linear model with treatment as a factor and baseline body weight and the same DXA parameter during the baseline DXA as covariates. Comparisons vs. vehicle of treatments were by Williams' test (ZGN-1061) and multiple $t$ test (beloranib). $* * * P<0.001$ vs. vehicle. 
TABLE 1

Effect of ZGN-1061 and beloranib on glycemic, lipid, and metabolic parameters at endpoint in DIO mice

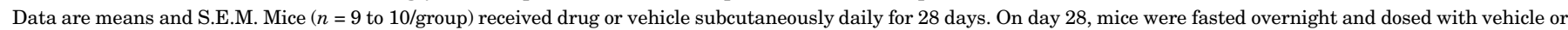

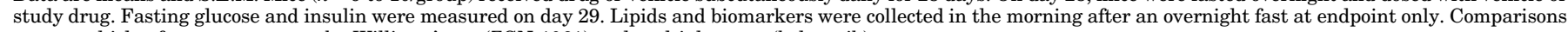
versus vehicle of treatments were by Williams' test (ZGN-1061) and multiple $t$ test (beloranib).

\begin{tabular}{|c|c|c|c|}
\hline & Vehicle & ZGN-1061 (0.3 mg/kg) & Beloranib $(0.1 \mathrm{mg} / \mathrm{kg})$ \\
\hline \multicolumn{4}{|l|}{ Glycemic parameters } \\
\hline Fasting glucose (mM) & $12.1 \pm 0.5$ & $8.8 \pm 0.3^{* * *}$ & $9.2 \pm 0.6^{* * *}$ \\
\hline Fasting insulin (ng/ml) & $2.63 \pm 0.16$ & $0.68 \pm 0.04 * * *$ & $1.27 \pm 0.16^{* * *}$ \\
\hline HOMA-IR (ratio) & $31.6 \pm 2.8$ & $6.1 \pm 0.9 * * *$ & $11.3 \pm 1.7^{* * *}$ \\
\hline \multicolumn{4}{|l|}{ Lipids } \\
\hline LDL cholesterol (mg/dl) & $48.5 \pm 5.2$ & $25.6 \pm 4.0^{* *}$ & $29.9 \pm 3.4^{* *}$ \\
\hline HDL cholesterol (mg/dl) & $225.7 \pm 11.1$ & $165.0 \pm 13.5^{* * *}$ & $192.6 \pm 14.7 *$ \\
\hline \multicolumn{4}{|l|}{ Metabolic biomarkers } \\
\hline$\beta$-hydroxybutyrate $(\mu \mathrm{mol} / \mathrm{l})$ & $514.0 \pm 57.9$ & $633.5 \pm 50.4^{*}$ & $630.7 \pm 41.4$ \\
\hline Leptin $(\mathrm{ng} / \mathrm{ml})$ & $31.3 \pm 3.6$ & $4.7 \pm 0.9 * * *$ & $6.6 \pm 1.1^{* * *}$ \\
\hline \multicolumn{4}{|l|}{ Liver target engagement } \\
\hline N-terminal thioredoxin $1-6$ (ng/mg total protein) & BLQ & $48.2 \pm 5.3$ & $37.2 \pm 4.7$ \\
\hline
\end{tabular}

BLQ, below the limit of quantitation; HDL, high-density lipoprotein; HOMA-IR, homeostatic model assessment-insulin resistance; LDL, low-density lipoprotein. $* P<0.05 ; * * P<0.01 ; * * * P<0.001$ vs. vehicle.

slightly (Fig. 2A). The difference in body weight between the ZGN-1061 or beloranib treatment groups versus vehicle was statistically significant as early as week 1 and persisted to the end of the study (week 4). The decrease in body weight in the ZGN-1061 and beloranib treatment groups was primarily due to a decrease in fat mass that was statistically significant for both ZGN-1061 and beloranib treatment groups versus vehicle at both weeks 2 and 4 (Fig. 2B). Consequently, the percent lean mass in the ZGN-1061 and beloranib treatment groups was significantly increased relative to vehicle at weeks 2 and 4 (Fig. 2C).

The difference in mean daily energy intake in the ZGN-1061 $(0.35 \pm 0.2 \mathrm{~kJ} / \mathrm{g}$ lean mass $)$ and beloranib $(0.34 \pm 0.3 \mathrm{~kJ} / \mathrm{g}$ lean mass) treatment groups were statistically significantly reduced compared with vehicle at week $2(0.49 \pm 0.1 \mathrm{~kJ} / \mathrm{g}$ lean mass) (both $P<0.001$ ). However, by week 4 , mean energy intake in the ZGN-1061 (0.47 $\pm 0.2 \mathrm{~kJ} / \mathrm{g}$ lean mass $)$ and beloranib $(0.47 \pm 0.3 \mathrm{~kJ} / \mathrm{g}$ lean mass $)$ treatment groups was comparable to vehicle $(0.47 \pm 0.1 \mathrm{~kJ} / \mathrm{g}$ lean mass $)(\mathrm{ns})$.

Improved fasting glucose and insulin was observed in DIO mice treated with ZGN-1061 and beloranib compared with control at the end of treatment. There was also a statistically significant reduction in HOMA-IR index with both MetAP2 inhibitors compared with vehicle (Table 1). In addition to statistically significant reduction of cholesterol (low-density and high-density lipoprotein cholesterol) compared with control, ZGN-1061 and beloranib also increased levels of $\beta$-hydroxybutyrate and reduced leptin. Target engagement as measured by the retention of $\mathrm{N}$-terminal methionine of thioredoxin (THX 1-6), a substrate for MetAP2 enzymatic activity, was increased from below the limit of detection in vehicle-treated mice to a similar degree by both ZGN-1061 and beloranib (Table 1).

In the hepatic HepG2 cell line, both ZGN-1061 and beloranib induced almost identical changes when compared with each other in global gene expression following either a 2- or 24-hour exposure at $6 \mathrm{nM}$ (Fig. 3, A and B). Genes that were significantly different from control for either ZGN-1061 or beloranib with a $P<0.01$ totaled 339 after 2-hour exposure and 2171 after 24-hour exposure. Correlation analysis showed a high degree of concordant regulation by both compounds with a Pearson coefficient $R^{2}=0.825(P<0.0001)$ at 2 hours and an $R^{2}=0.9151(P<0.0001)$ at 24 hours. Examples of coordinately regulated genes after 2 hours exposure are shown in Fig. 3, C-E and include genes involved in regulation of body weight (growth and differentiation factor 15), mitochondrial function (peroxisome proliferator-activated receptor gamma, coactivator-related 1), and glucose metabolism (serum/ glucocorticoid regulated kinase 1).

Effects of ZGN-1061 and Beloranib on EC Proliferation. Because venous ECs actively modulate coagulation and MetAP2 inhibitors have demonstrated effects on EC growth (Kusaka et al., 1991), the effect of ZGN-1061 and beloranib on inhibition of EC proliferation after exposure to various concentrations and incubation durations was studied in HUVECs. ZGN-1061 and beloranib decreased EC proliferation with continuous exposure over the 72-hour treatment period in a concentration-dependent manner (Fig. 4A). Both drugs were equally potent; the concentration that inhibited EC proliferation by $50 \%\left(\mathrm{EC}_{50}\right)$ values were 0.24 and $0.27 \mathrm{nM}$ for ZGN-1061 and beloranib, respectively. The effect of duration of exposure on inhibition of EC proliferation was evaluated using shorter incubation times of $1,4,8,24$, and 48 hours. Robust inhibition of EC proliferation was observed with ZGN-1061 only when exposure was continuous for 48 hours or longer (Fig. 4B). Short-term exposure (4 hours or less) of ECs to ZGN-1061 at concentrations up to $50 \times$ the $\mathrm{EC}_{50}$ had no effect on cell proliferation. In contrast, beloranib effects on EC proliferation occurred rapidly, with exposures as short as 1 hour, with effects starting as low as $11 \times$ the $\mathrm{EC}_{50}$ (Fig. 4C).

Effects of ZGN-1061 and Beloranib on Coagulation Markers in ECs. Cell protein levels of cell cycle regulators p53 and p21 and markers of EC coagulation, TM, PAI-1, and vWF were evaluated following exposure of 1,10 , or $20 \mathrm{nM}$ of ZGN-1061 or beloranib. Neither ZGN-1061 nor beloranib altered p53 or vWF protein levels at any of the incubation times (data not shown). All concentrations of ZGN-1061 increased p21 and reduced TM protein levels after 72 hours of incubation, but there were no meaningful changes with shorter incubations of 4 or 8 hours (Fig. 5). Beloranib also increased p21 and reduced TM levels after 72 hours of incubation at all concentrations. In contrast, short 4- or 8-hour incubations with the higher concentrations of beloranib (10 and $20 \mathrm{nM}$ ) increased $\mathrm{p} 21$ and reduced TM protein levels. ZGN-1061 had no effect on PAI-1 protein levels at any 


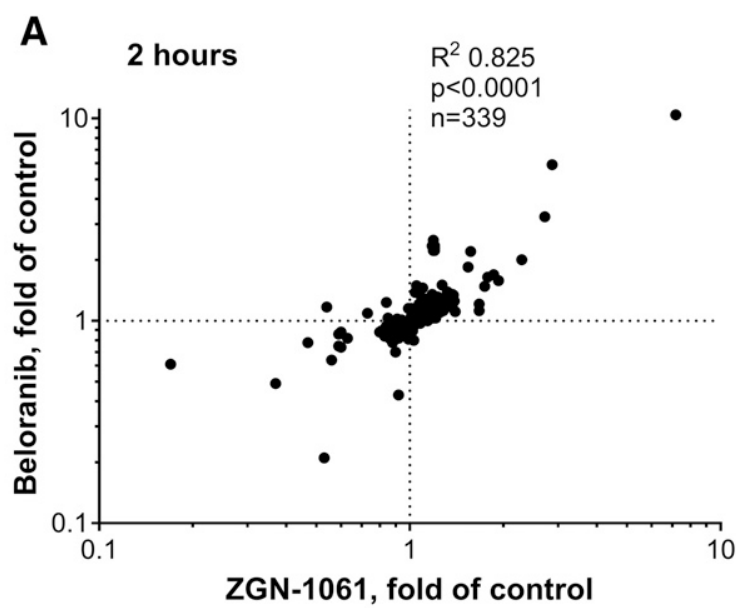

C

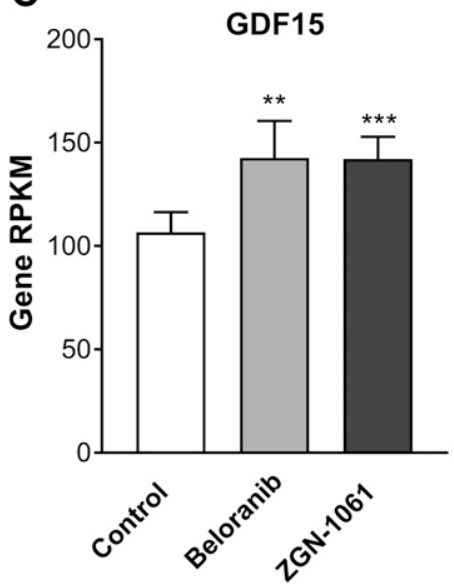

D
B
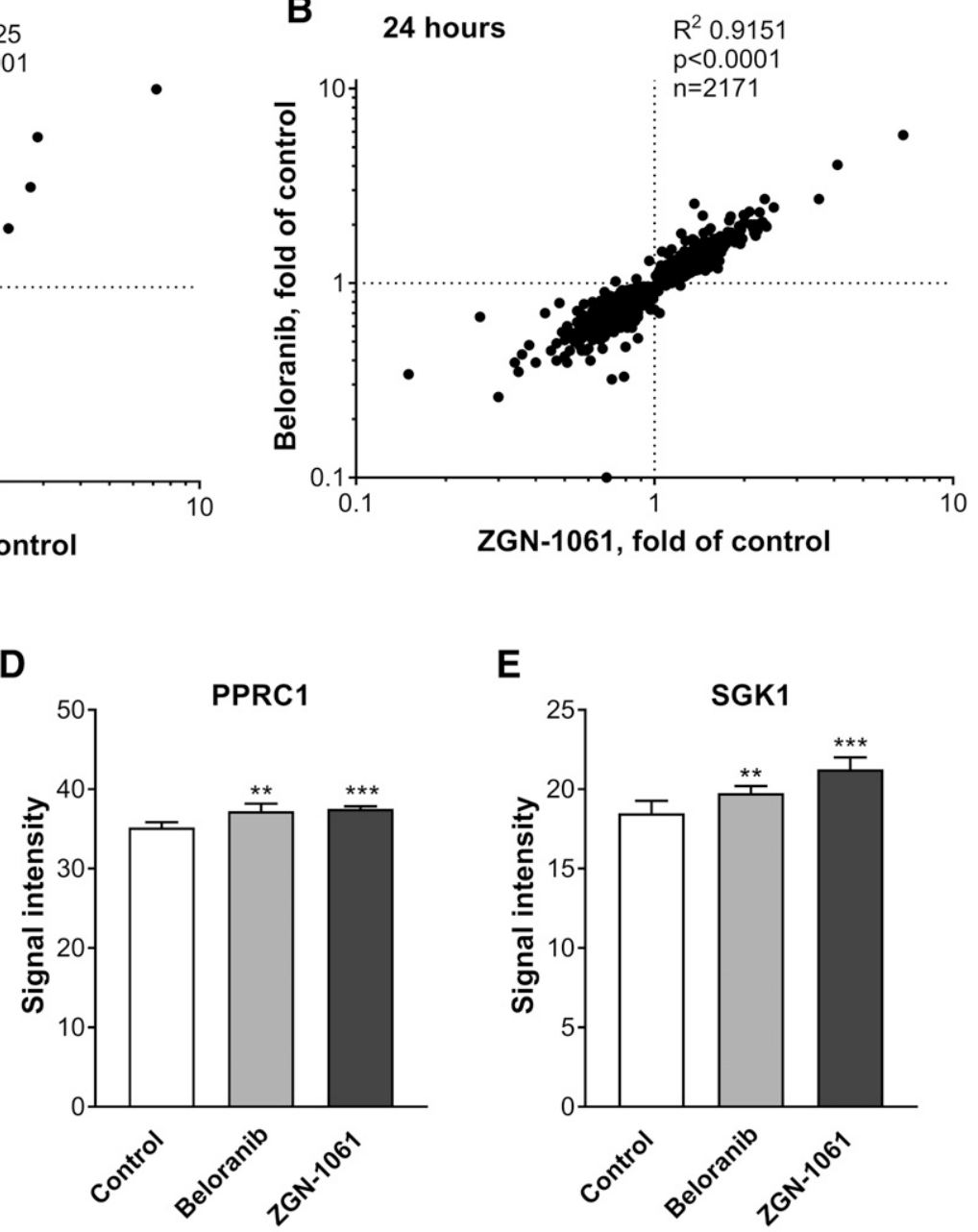

E

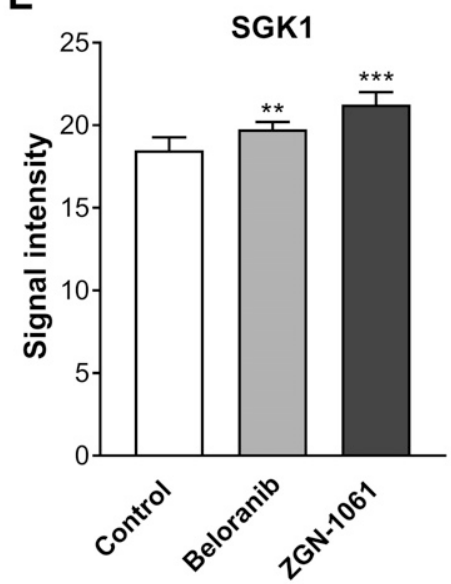

Fig. 3. RNAseq analysis of HepG2 cell gene expression from cells treated with ZGN-1061 or beloranib at 6 nM for 24 hours. (A and B) Genes that were significantly different by Tukey's one-way analysis of variance (ANOVA) with $P<0.01$ relative to control by either ZGN-1061 or beloranib were correlated at 2 or 24 hours. (C-E) RPKM for selected genes for control, ZGN-1061, and beloranib (mean and S.D., $n=4$ per group); Tukey's one-way ANOVA; $* * P<0.01 ; * * * P<0.001$ vs. control. GDF-15, growth and differentiation factor 15 ; PPRC1, peroxisome proliferator-activated receptor gamma, coactivator-related 1; SGK1, serum/glucocorticoid regulated kinase 1.

of the concentrations or time points, whereas beloranib increased PAI-1 levels at all concentrations at 72 hours and at 10 and $20 \mathrm{nM}$ at the earliest timepoint (Fig. 5).

MetAP2 Target Engagement Studies of ZGN-1061 and Beloranib in ECs and HepG2 Cells. The effects of ZGN-1061 and beloranib on MetAP2 target engagement was conducted in HUVECs. Incubation of HUVECs with 10, 30, or $100 \mathrm{nM}$ of ZGN-1061 or beloranib for 1 hour followed by washing away of compound from the culture media resulted in a more than 10-fold higher cell-associated concentration of beloranib compared with cell-associated levels of ZGN-1061 at any given incubation concentration (Fig. 6A). Despite the differences in cell-associated drug levels, there were similar amounts of drug bound covalently to the MetAP2 active site across the concentration range for both ZGN-1061 and beloranib (Fig. 6B). Thus, similar and maximal binding to MetAP2 protein occurred with the $10 \mathrm{nM}$ concentration of both ZGN1061 and beloranib and subsequent MetAP2 target engagement studies employed a $10 \mathrm{nM}$ concentration of both drugs.

A second experiment was conducted in ECs to address if preincubation of the MetAP2 enzyme with a saturating concentration of ZGN-1061 (10 nM) would prevent subsequent binding by beloranib (10 $\mathrm{nM})$ and influence cell proliferation, MetAP2 target engagement, or MetAP2 enzymatic activity. HUVECs were evaluated at various times over a 72-hour period after a 2-hour incubation with either ZGN-1061 alone, beloranib alone, or a sequential 1-hour incubation with ZGN1061 followed by a 1-hour incubation with beloranib (Fig. 7A). ZGN-1061 alone had no effect on cell proliferation when measured at 72 hours, whereas beloranib alone reduced cell proliferation by approximately $60 \%$ (Fig. 7B). When HUVECs were first exposed to ZGN-1061 for 1 hour, then drug was washed out, then subsequently exposed to beloranib for 1 hour, and again drug was washed out, the result was an inhibition of cell proliferation (Fig. 7B), indicating that preincubation with ZGN-1061 does not prevent subsequent inhibition of cell proliferation by beloranib.

MetAP2 target engagement was assessed by measuring the concentration of MetAP2 protein with drug covalently bound to the active site His-231 residue (Fig. 7C). In cells that were exposed to only ZGN-1061 for 2 hours, target engagement decreased over the 72-hour time period. In contrast, in cells 


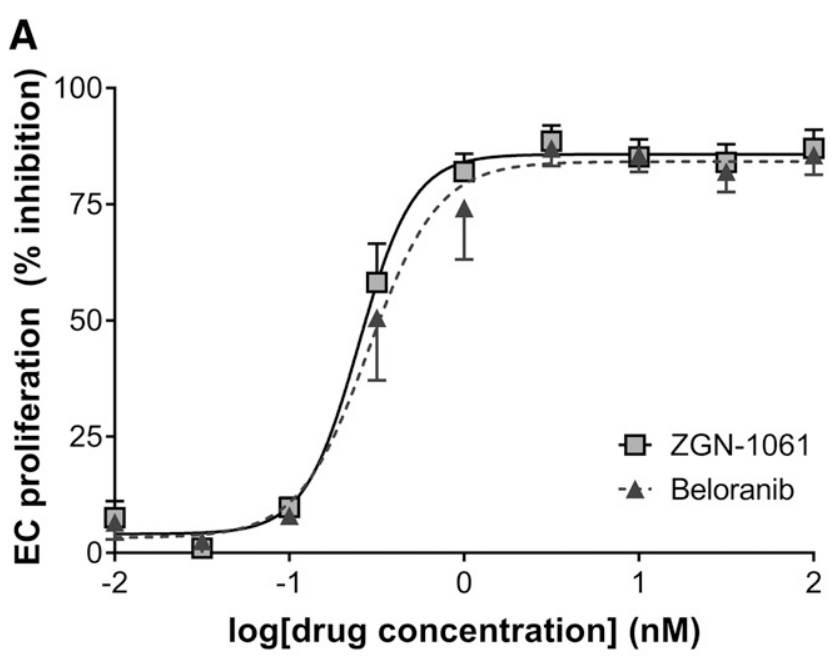

B

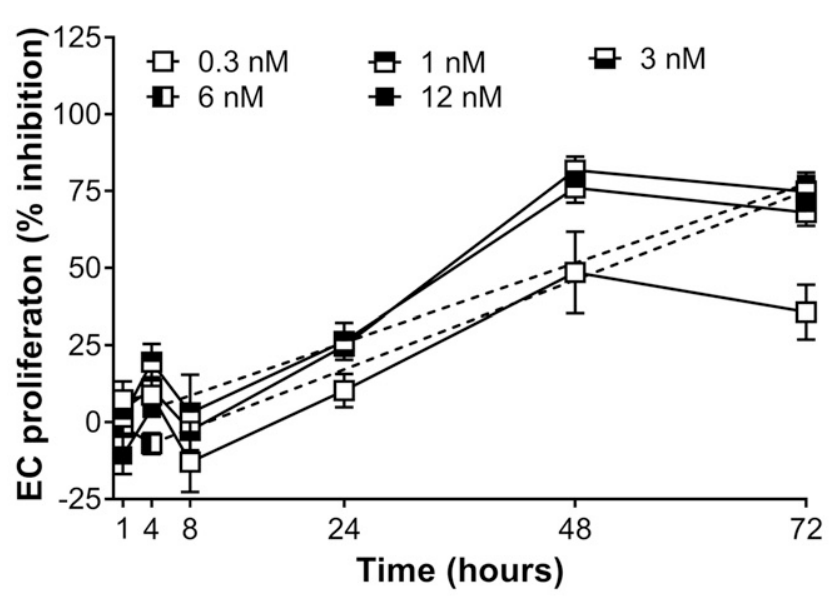

C

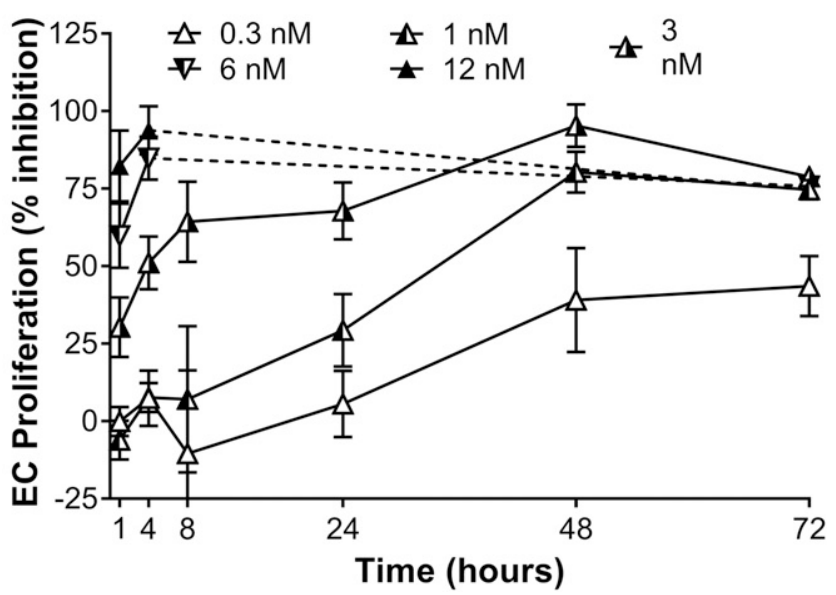

Fig. 4. Data are mean and S.E.M. (A) Inhibition of EC proliferation was assessed in HUVECs ( $n=5$ replicates/group) after incubation in various concentrations of drug for 72 hours. (B and $\mathrm{C}$ ) Inhibition of EC proliferation was assessed in HUVECs after incubation with ZGN1061 ( $n=4-9$ replicates/group) or beloranib ( $n=4-8$ replicates/group) for $1,4,8,24,48$, and 72 hours. Inhibition of proliferation was measured at 1, 4, and 72 hours for 6 and $12 \mathrm{nM}$ concentrations of ZGN-1061 and beloranib. exposed to only beloranib for 2 hours, target engagement was persistent across the 72-hour time period. Following sequential exposures of ZGN-1061 for 1 hour, then beloranib for 1 hour, only ZGN-1061 initially occupied the MetAP2 enzyme active site. With continued culture, ZGN-1061 in the enzyme active site was gradually replaced by beloranib over the 72-hour period, despite both compounds being washed after the initial 2-hour incubation. Target engagement of the MetAP2 enzyme can also be measured functionally through the accumulation of the MetAP2 substrate thioredoxin that retains its intact $\mathrm{N}$-terminal methionine residue (THX 1-6). Figure 7D shows that the THX 1-6 concentrations were consistently low over the 72-hour culture following exposure to only ZGN-1061 for 2 hours. In contrast, a 2-hour exposure to beloranib resulted in a marked increase of THX 1-6 over the 72 hours. In the case of sequential exposure of ZGN-1061 (1 hour) followed by beloranib (1 hour), the levels of THX 1-6 were also markedly increased over the 72 hours, indicative of sustained target engagement in beloranib-exposed EC cells despite no ongoing extracellular exposure to the drug.

Target engagement kinetics were also assessed in HepG2 cells. For this assessment, HepG2 cells were exposed to either ZGN-1061 or beloranib for 2 hours. Drug was then washed out and levels of MetAP2 with drug bound in the active site were measured. Figure 8A shows that both ZGN-1061 and beloranib are found in the active site of MetAP2 after the 2-hour exposure. Upon further culture, the proportion of MetAP2 that contained drug in the active site declined similarly over the 72 hours for both ZGN-1061 and beloranib. In comparison, HUVECs exposed to the drug in a similar manner showed a sustained level of beloranib in the MetAP2 active site over 72-hour culture, whereas ZGN-1061 target engagement declined (Fig. 8B).

Pharmacokinetic Studies of ZGN-1061 and Beloranib in Dogs. Figure 9 shows plasma drug concentrations after a single subcutaneous injection in dogs (day 1). In dogs, ZGN1061 concentrations quickly reached the maximum observed concentration $\left(C_{\max }\right)$ and rapidly declined to undetectable concentrations within a few hours after dosing (Fig. 9). The half-life $\left(t_{1 / 2}\right)$ of ZGN-1061 was 0.4 hours in dogs. In contrast, the $C_{\max }$ for beloranib occurred 4 or more hours after administration and beloranib plasma concentrations declined much more slowly. The $t_{1 / 2}$ for beloranib was 9.3 hours in dogs.

Effects of ZGN-1061 and Beloranib on Coagulation Markers in Dogs. In studies of beloranib toxicology in dogs, some animals developed evidence of impaired hemostasis (i.e., marked reductions in platelet count, bleeding gums, bloody stool) within 2 weeks of drug administration at doses of $0.6 \mathrm{mg} / \mathrm{kg}$ s.c. every 3 days. This altered hemostasis led to a focused investigation of the effects of ZGN-1061 and beloranib on hematology and coagulation parameters in dogs over the first 10 days of treatment. ZGN-1061 ( $2 \mathrm{mg} / \mathrm{kg}$ s.c. every 3 days) administered to dogs for 10 days was well tolerated and produced no adverse changes in clinical observations, hematology (e.g., platelet count), or the coagulation markers, D-dimer, thrombin time, and antithrombin III (Fig. 10). Weight loss was observed over the course of the study, but food intake was unchanged, and all animals survived through the scheduled dosing period. In a separate study, beloranib $(0.6 \mathrm{mg} / \mathrm{kg}$ s.c. every 3 days) administration to dogs was accompanied by increased D-dimer concentrations and decreased thrombin time, antithrombin III, and platelet count (Fig. 10). At $0.6 \mathrm{mg} / \mathrm{kg}$, 

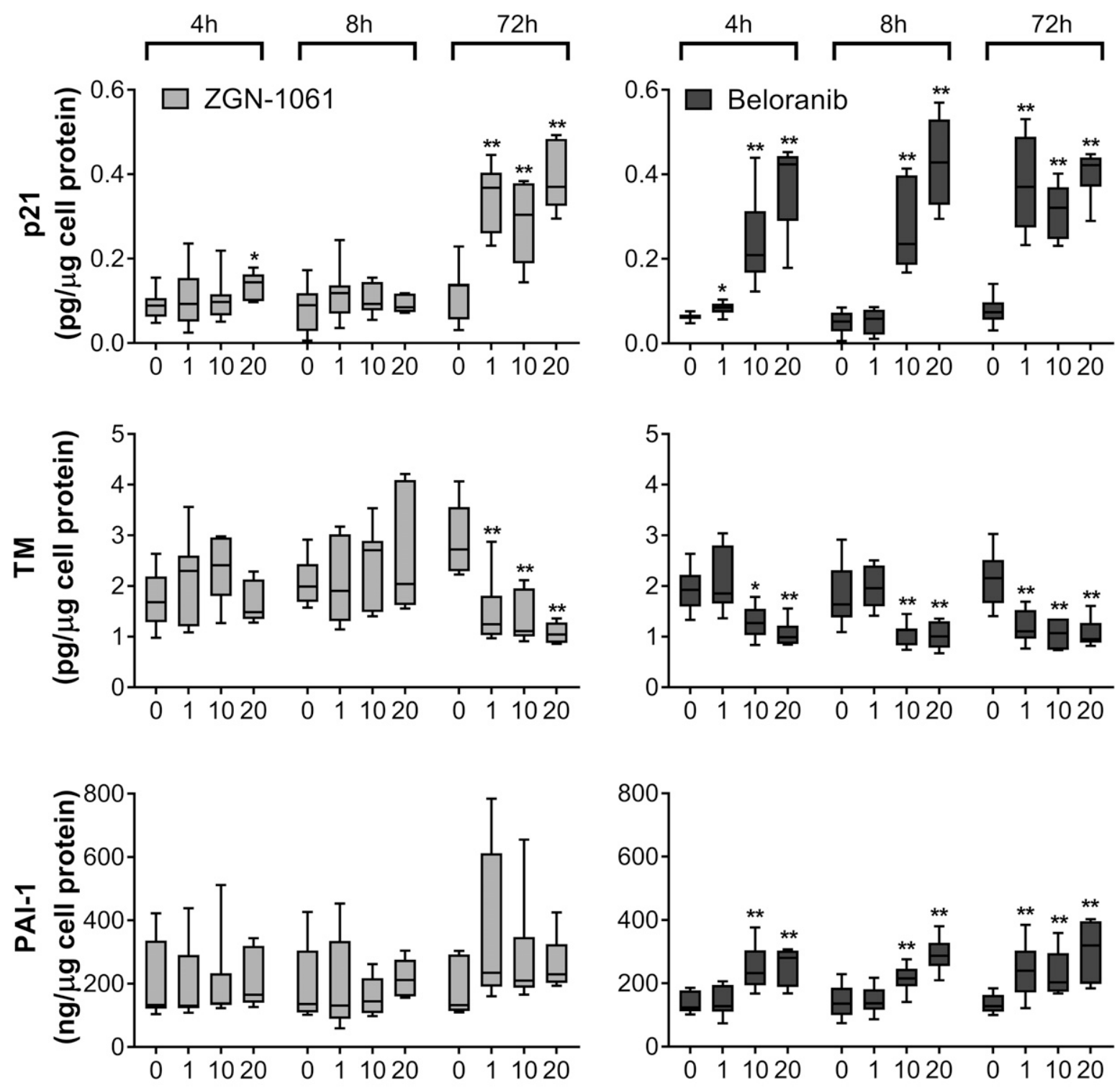

Drug concentration $(\mathrm{nM})$

Fig. 5. Data are median, 25th, and 75th percentile, and minimum/maximum. HUVECs were maintained in the presence of $0,1,10,20 \mathrm{nM} Z \mathrm{ZGN}$ - 1061 or beloranib for 4,8 , or 72 hours followed by assessment of cell protein concentrations. $N=5-10$ replicates/test condition. ${ }^{*} P<0.05$ vs. control $(0 \mathrm{nM})$ and $* * P<0.005$ vs. control.

beloranib was not well tolerated, with fecal changes, lethargy, emesis, red and/or black feces, and decreased activity.

Toxicology Studies of ZGN-1061 and Beloranib in the Rat. Table 2 illustrates safety comparisons between ZGN1061 and beloranib administered subcutaneously every 3 days for approximately 28 days in rat toxicology studies. For beloranib, doses ranging from 0.2 to $6 \mathrm{mg} / \mathrm{kg}$ were tested, where no observed adverse effect levels (NOAELs) of 0.6 (males) and $2 \mathrm{mg} / \mathrm{kg}$ (females) were established. At the highest dose, mortality was noted by days 16-24, and this dose was decreased to $4 \mathrm{mg} / \mathrm{kg}$. However, the dose was also not tolerated and the males in this group were terminated on day 26 . In contrast, ZGN-1061 doses ranged from 2 to $25 \mathrm{mg} / \mathrm{kg}$, no mortality was noted, and the highest dose was well tolerated. The most notable finding was the increased degree of irritation and inflammation at the injection site in animals receiving the highest dose of $\mathrm{ZGN}-1061$ (25 mg/kg). After the 10 -week recovery period, the lesions were mainly resolved with generally minimal fibrosis noted in 3/10 rats. Other findings of generally minimal grade and low incidence were mixed cell inflammation in lung (minimal to mild) and minimal individual hepatocellular necrosis (that resolved after dosing was stopped). With respect to exposure at the NOAEL, $C_{\max }$ and area under the curve from time 0 to the last measurable time point $\left(\mathrm{AUC}_{0-t}\right)$ were markedly higher with ZGN-1061 compared with beloranib. For example, the repeat dose $\mathrm{AUC}_{0-t}$ for males and females was 409 and $288 \mathrm{ng} \times$ hour/ $\mathrm{ml}$ for ZGN-1061, respectively, versus 29.0 and $56.7 \mathrm{ng} \times$ hour/ $\mathrm{ml}$ for beloranib, respectively, indicating exposures ranging from 5- to 14-fold higher at the NOAEL for ZGN-1061. Greater exposure differences for ZGN-1061 versus beloranib were observed for the $C_{\max }$ (21- to 52 -fold). 
A

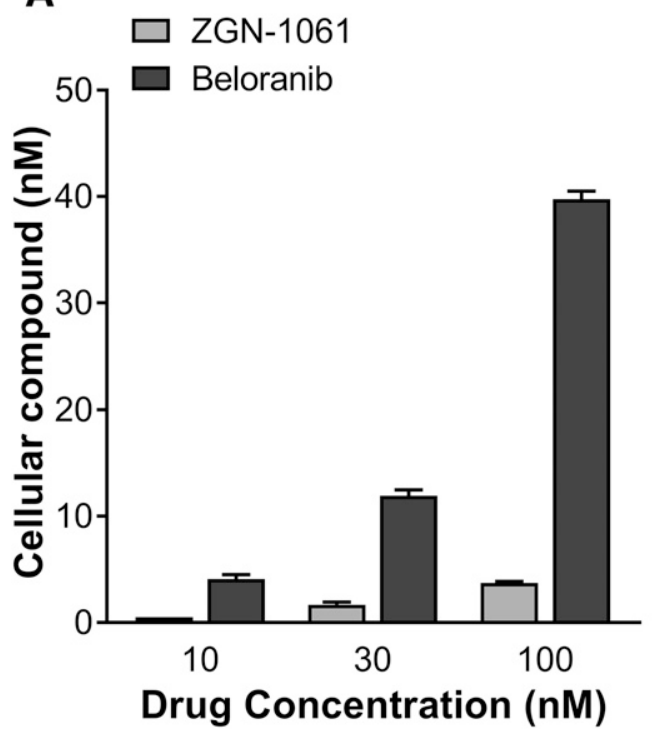

B

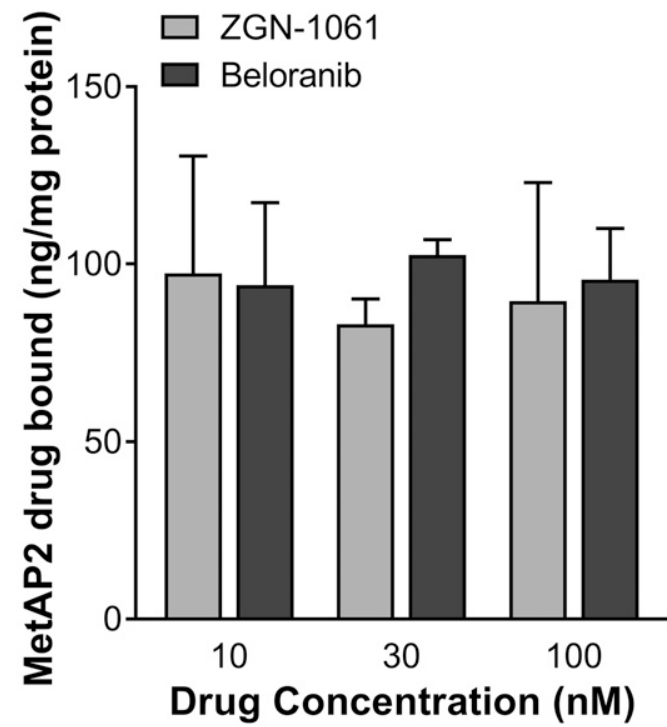

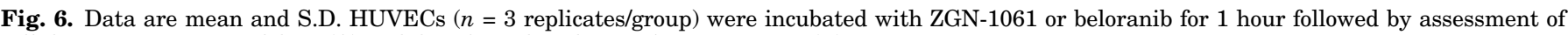
cellular concentrations of drug (A) and drug bound to the MetAP2 active site (B).

\section{Discussion}

Here, we report the pharmacological efficacy and nonclinical safety of the novel MetAP2 inhibitor ZGN-1061 compared with a MetAP2 inhibitor previously in development, beloranib. These studies demonstrate that ZGN-1061 has an efficacy profile similar to beloranib, resulting in marked reductions in body weight and improvements in glycemic control, lipid metabolism, and other metabolic parameters in DIO mice. The transcriptional profile induced by both compounds was also highly concordant in the HepG2 cell line, including genes that can be linked to efficacy observed in mice. However, ZGN-1061 had a substantially improved safety profile compared with beloranib in multiple nonclinical studies of safety and toxicity.

In DIO mice that are characterized by excess adiposity and insulin resistance, 4-week treatment with ZGN-1061 and beloranib at their respective maximally effective doses produced similar weight loss, reduced fat mass, and improvements in glucose, insulin, cholesterol, $\beta$-hydroxybutyrate, and leptin. The $0.3 \mathrm{mg} / \mathrm{kg}$ ZGN-1061 dose had similar liver THX 1-6 as the $0.1 \mathrm{mg} / \mathrm{kg}$ beloranib dose, demonstrating similar tissue target engagement for the selected doses. Both ZGN-1061 and beloranib induced a very similar effect on gene expression in the HepG2 hepatoma cell line. The highly concordant effect of both compounds with exposures as short as 2 hours demonstrates that the effect of MetAP2 inhibition occurs rapidly and becomes increasingly robust with additional exposure to 24 hours. The compound-mediated change in gene expression include genes that would be expected to contribute to the antiobesity and antidiabetic effects observed in both animal models and humans who are obese and/or diabetic.

In clinical studies, beloranib was associated with an increased incidence of venous thromboembolism. ECs are known to be affected by MetAP2 inhibitors, especially for inhibition of proliferation (Kusaka et al., 1991; Zhang et al., 2000). In vascular ECs, increased EC proliferation is observed, especially at sites of high sheer stress where repair is important to ensure the endothelial lining remains intact (Schwartz, 1982). In the vascular endothelium, p53 overexpression leads to a procoagulant response, including facilitation of the coagulation cascade by altering the display of pro- and anticoagulant proteins (Kumar et al., 2011) and accumulation of p21, leading to G1 cell cycle arrest. Previous work has shown that TNP-470, a MetAP2 inhibitor, induces G1 cell cycle arrest and inhibition of HUVEC proliferation (Kusaka et al., 1991), an effect that was ascribed to upregulated p21, leading to cell cycle arrest and induction of a procoagulable state (Zhang et al., 2000). Cell cycle arrest also controls cell growth and replication in settings of reduced growth factor and nutrient supply that is controlled by a cell growth check point (Foster et al., 2010). This growth check point occurs late in G1 and may require up to a day to achieve in HUVECs that have a doubling time of 24-48 hours. Results from our current studies are consistent with chronic exposure ( $>24$ hours) of HUVECs to MetAP2 inhibitors increasing P21 protein, inducing a G1 cell cycle arrest, and inhibiting proliferation that is associated with changes in coagulation factors TM and PAI-1.

An important observation from these studies is that short exposures, 8 hours or less, which are representative of therapeutic exposures in vivo, of HUVECs to ZGN-1061 neither inhibited EC proliferation nor altered levels of procoagulant proteins. The transient binding of MetAP2 by ZGN1061 may have effects that wear off before reaching the restriction point for committing to G1 cell cycle arrest. In contrast, exposures to beloranib as short as 1 or 4 hours were sufficient to inhibit EC proliferation and alter procoagulant proteins, respectively. These results demonstrate a fundamentally different effect of beloranib on ECs compared with ZGN-1061 and suggest that if duration of exposures of ECs to ZGN-1061 or other MetAP2 inhibitors are kept short, the adverse procoagulant effect of beloranib can be avoided. As discussed below, this concept has been confirmed in dogs, where a substantially improved margin of safety for procoagulant activity has been observed for ZGN-1061 relative to beloranib and correlates with reduced duration of exposure. 
A

\section{HUVEC study design}
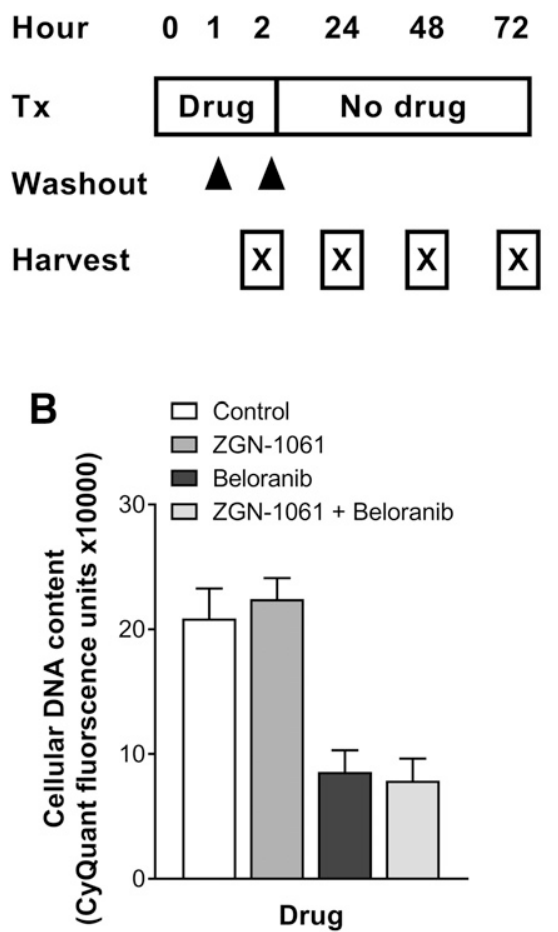
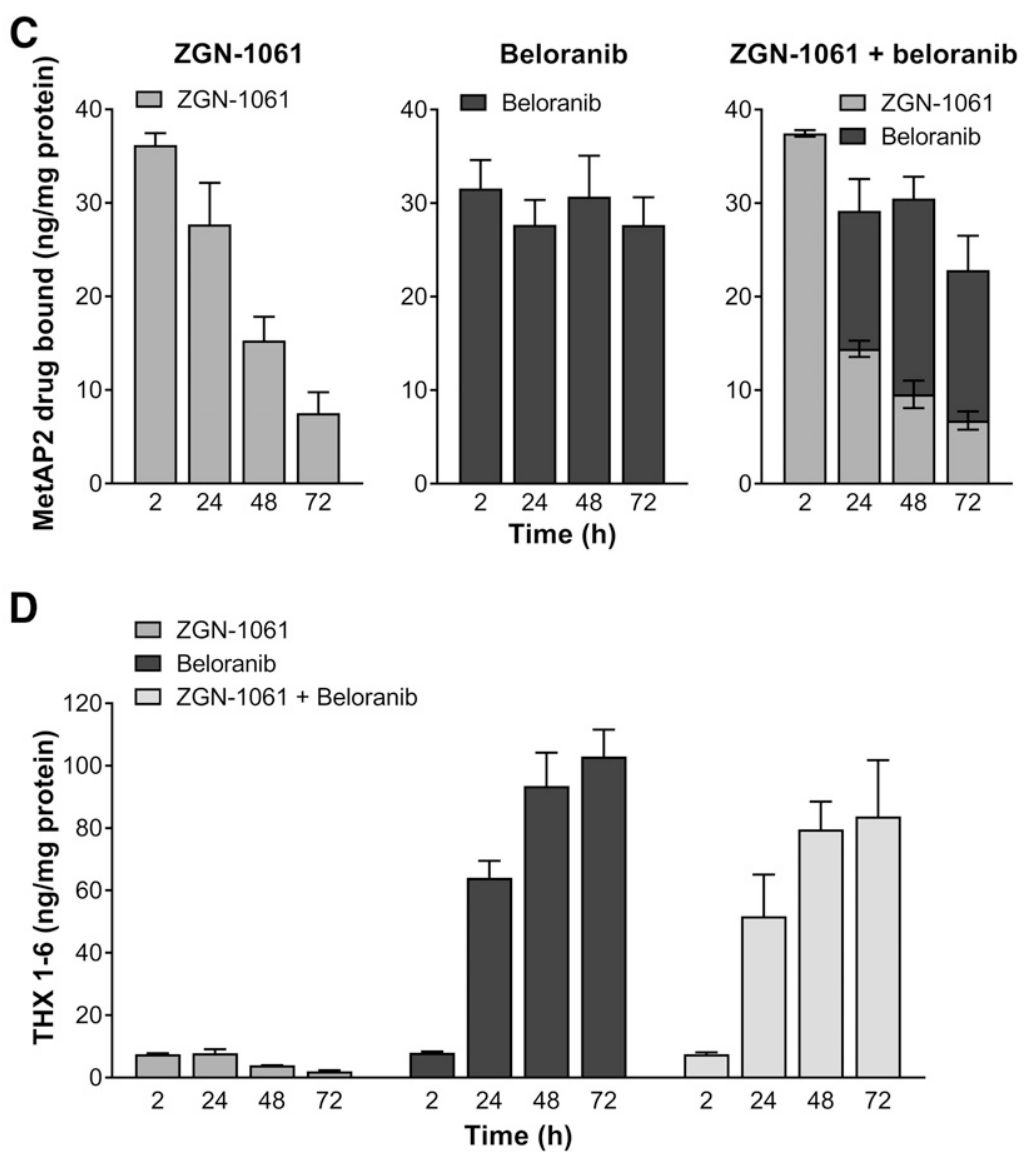

Fig. 7. Data are mean and S.D. Drug concentration was $10 \mathrm{nM}$. (A) HUVECs ( $n=9$ replicates/group) were incubated with drug or vehicle (control) for 1 hour and cells were washed and incubated an additional hour with drug or vehicle and again washed and immediately harvested or placed in drug-free media and harvested at 24, 48, or 72 hours. (B) Cell proliferation (DNA content) was assessed 72 hours after the start of the first incubation. (C) Drug bound to MetAP2 was assessed 2, 24, 48, or 72 hours after the start of the first incubation. (D) THX 1-6 was assessed 2, 24, 48, or 72 hours after the start of the first incubation.

Studies of MetAP2 target engagement and enzymatic activity in ECs demonstrated that levels of MetAP2 protein with ZGN-1061 bound in the active site declined over time, whereas levels of MetAP2 with beloranib in the active site were sustained over the 72 hours, even following brief exposures. Given the covalent binding mode of ZGN-1061,
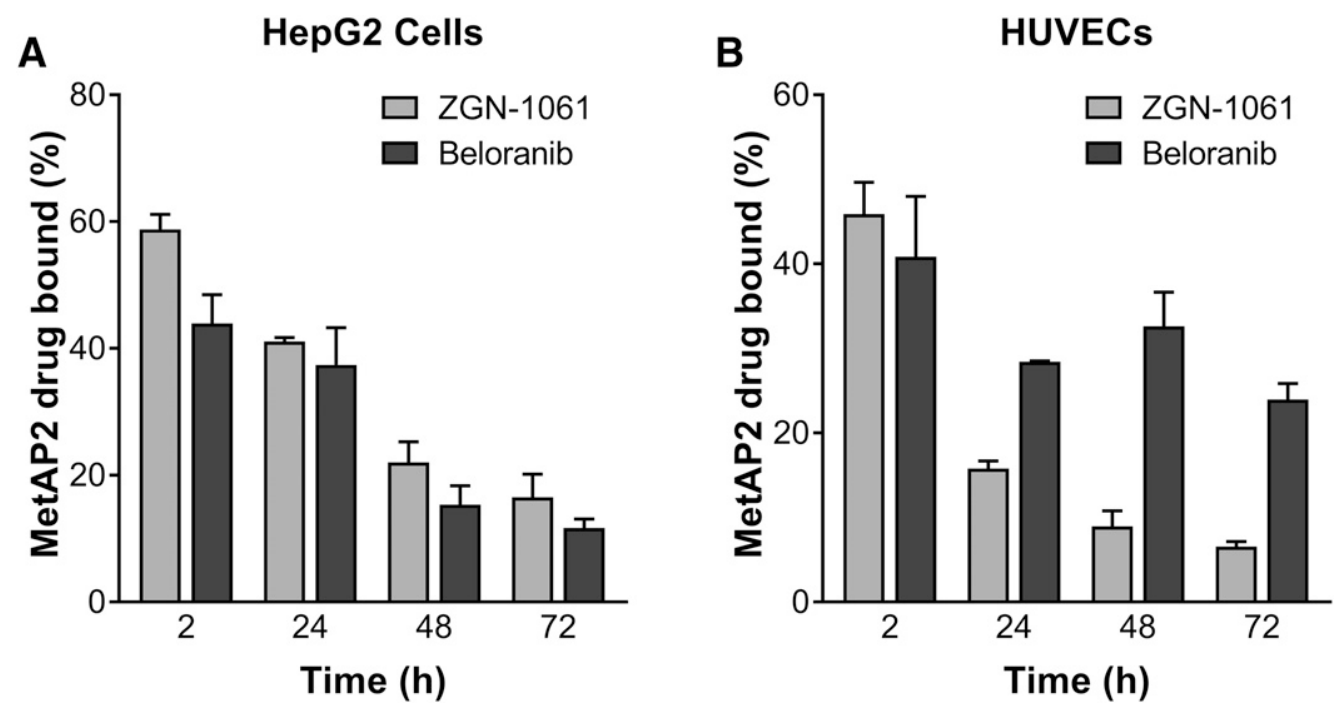

Fig. 8. Data are mean and S.D. (A) HepG2 cells $(n=3)$ and (B) HUVECs $(n=3)$ were incubated with ZGN-1061 or beloranib for 2 hours, washed, incubated in drug-free media, and harvested at $2,24,48$, or 72 hours. Cell lysates were used to measure MetAP2 protein with drug bound in the active site, normalized to total MetAP2. 


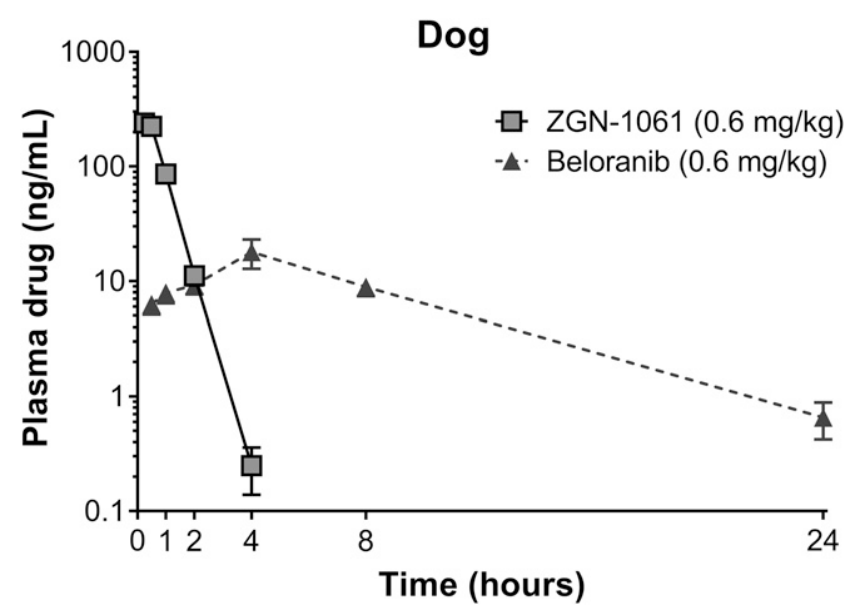

Fig. 9. Mean and S.D. plasma ZGN-1061 and beloranib concentrations following acute subcutaneous administration in dogs ( $n=8-10$ /group). ZGN-1061 was undetectable in plasma after the 4-hour time point in dogs.

the decline of MetAP2 protein with ZGN-1061 bound in the active site is presumably due to degradation and turnover of the MetAP2 protein. The persistence of beloranib bound in the MetAP2 active site in cells is due either to an inhibition of the degradation and turnover of drug-bound MetAP2 protein and/ or creation of a reservoir of beloranib drug in the endothelial cell that can diffuse over time to bind and inhibit newly available MetAP2 protein. The results support the latter of these explanations for two reasons. First, following a 1-hour incubation and washing of cells to remove compound, the concentrations of cell-associated beloranib were approximately 10-fold higher that ZGN-1061, supporting greater loading and/or accumulation of beloranib in the cell. Second, although prebinding MetAP2 with ZGN-1061 initially saturated MetAP2 target engagement, the levels of MetAP2 protein with ZGN-1061 bound in the active site declined over time (supporting enzyme turnover) and MetAP2 with beloranib in the active site increased. For this to occur, a reservoir of beloranib was likely generated following brief exposure in the HUVECs to engage newly available MetAP2 protein over time. The beloranib chemical structure features a basic nitrogen with a high $\mathrm{p} K_{\mathrm{a}}(9.4)$ that makes it prone to protonation in acidic conditions, whereas ZGN-1061 lacks this structural feature and has a lower $\mathrm{p} K_{\mathrm{a}}$ (7.17). Some compounds with high $\operatorname{cLogP}(>4)$ and $\mathrm{p} K_{\mathrm{a}}(>8)$ can be trapped through protonation and accumulate in the lysosome (Hu et al., 2012; Khoh-Reiter et al., 2015). Additional studies are warranted to understand the unique reservoir of beloranib in ECs that leads to prolonged target engagement and increased procoagulant activity. The persistent MetAP2 target engagement by beloranib in HUVECs may be a unique feature of ECs because the hepatoma HepG2 cell line did not show the same persistence of beloranib target engagement over the 72-hour experiment. The transient target engagement of ZGN-1061 may be insufficient to trigger a cell growth checkpoint that induces G1 arrest. In contrast, beloranib's persistent MetAP2 target engagement may be sufficient to trigger a cell growth checkpoint that initiates G1 arrest and inhibition of proliferation.

The differences between the safety profiles of beloranib and ZGN-1061 also may be attributable, in part, to differences in their physicochemical, PK, distributional, and metabolic profiles. ZGN-1061 is substantially more water soluble than beloranib, and consequently it can be administered as an
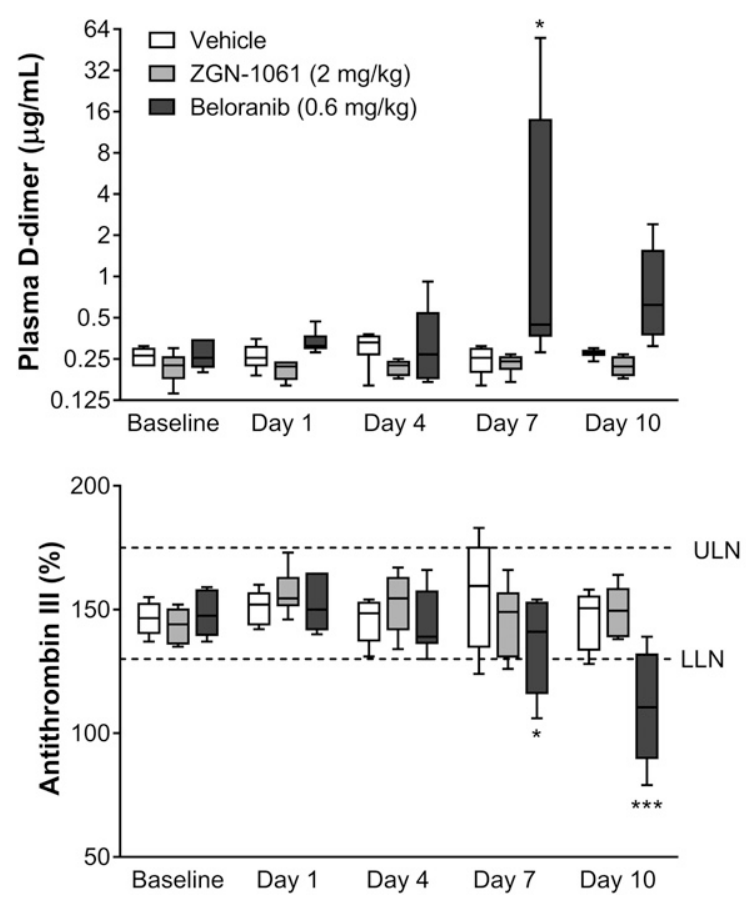
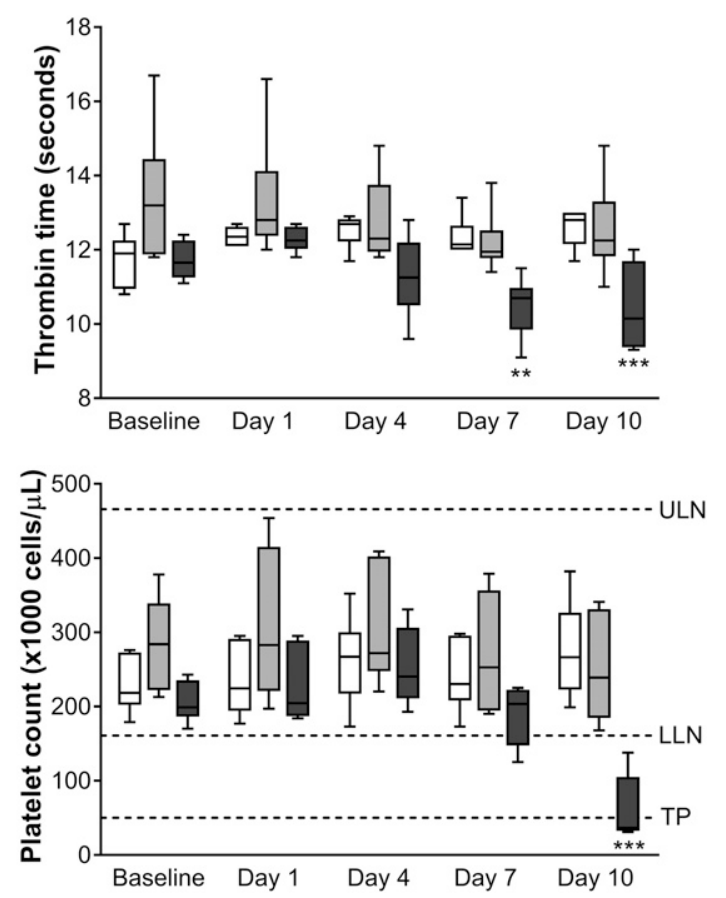

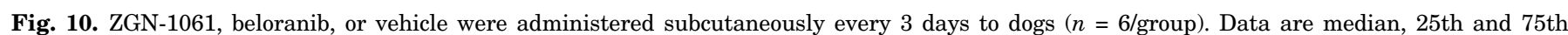

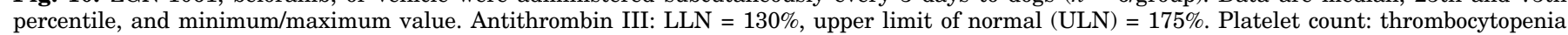

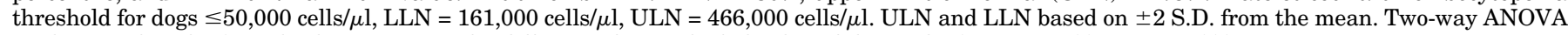
analysis with Tukey's multiple comparison for difference from vehicle by day of the study, $* P<0.05$; $* * P<0.01 ; * * * P<0.001$. 
TABLE 2

Comparison of toxicological findings after 4 weeks of exposure with ZGN-1061 and beloranib Male and female rats were dosed with ZGN-1061 ( $n=15$ /group) or beloranib ( $n=20$ /group).

\begin{tabular}{|c|c|c|}
\hline & ZGN-1061 & Beloranib \\
\hline Dose (subcutaneous every 3 days) & $0,2,6$, and $25 \mathrm{mg} / \mathrm{kg}$ & $0,0.2,0.6,2$, and $6 \mathrm{mg} / \mathrm{kg}^{a}$ \\
\hline NOAEL & $6 \mathrm{mg} / \mathrm{kg}(\mathrm{M}, \mathrm{F})$ & $0.6 \mathrm{mg} / \mathrm{kg}(\mathrm{M}), 2 \mathrm{mg} / \mathrm{kg}(\mathrm{F})$ \\
\hline Mortality/early euthanasia & None & $\begin{array}{l}4 / 15 \text { males in the } 6 \mathrm{mg} / \mathrm{kg} \text { dose group died by } \\
\text { day } 24 \text {, and the remaining males in the } 6 \mathrm{mg} / \mathrm{kg} \\
\text { group were euthanized on day } 26\end{array}$ \\
\hline \multicolumn{3}{|r|}{ group were eutrantzed on day zo } \\
\hline \multirow[t]{4}{*}{$\begin{array}{l}\text { Target organs: finding, grade } \\
\text { (dose, } \mathrm{mg} / \mathrm{kg} \text { ) }\end{array}$} & $\begin{array}{l}\text { Treatment site: irritation, inflammation, seroma } \\
\text { formation }(25 \mathrm{mg} / \mathrm{kg})\end{array}$ & Spleen: decreased cellularity, minimal ( $\geq 2 \mathrm{mg} / \mathrm{kg}$ ) \\
\hline & Lung: mixed cell inflammation, mild ( $25 \mathrm{mg} / \mathrm{kg})$ & $\begin{array}{l}\text { Bone marrow: decreased cellularity, minimal to } \\
\text { moderate with increased fat }(\geq 2 \mathrm{mg} / \mathrm{kg})\end{array}$ \\
\hline & Liver: necrosis, minimal (25 mg/kg) & $\begin{array}{l}\text { Thymic atrophy: lymphoid depletion, minimal to } \\
\text { mild ( } \geq 2 \mathrm{mg} / \mathrm{kg})\end{array}$ \\
\hline & & $\begin{array}{l}\text { Testes: germ cell depletion/degeneration and } \\
\text { marked Leydig cell atrophy, minimal to severe } \\
(\geq 2 \mathrm{mg} / \mathrm{kg})\end{array}$ \\
\hline \multicolumn{3}{|r|}{$(=2 \mathrm{mg} / \mathrm{kg})$} \\
\hline \multicolumn{3}{|l|}{ AUC $_{0-t}$ at NOAEL $(\mathrm{ng} \times \mathrm{h} / \mathrm{ml})$} \\
\hline Day 1 & $349(\mathrm{M}), 262(\mathrm{~F})$ & $36.8(\mathrm{M}), 96.9(\mathrm{~F})$ \\
\hline Days $28 / 31^{b}$ & $409(\mathrm{M}), 288(\mathrm{~F})$ & $29.0(\mathrm{M}), 56.7(\mathrm{~F})$ \\
\hline \multicolumn{3}{|l|}{$C_{\max }$ at NOAEL $(\mathrm{ng} / \mathrm{ml})$} \\
\hline Day 1 & $351(\mathrm{M}), 278(\mathrm{~F})$ & $19.2(\mathrm{M}), 28.5(\mathrm{~F})$ \\
\hline Days $28 / 31^{b}$ & $426(\mathrm{M}), 412(\mathrm{~F})$ & $8.17(\mathrm{M}), 19.2(\mathrm{~F})$ \\
\hline
\end{tabular}

\footnotetext{
${ }^{a}$ Dose decreased from 6 to $4 \mathrm{mg} / \mathrm{kg}$ after mortality was observed in male rats during days $16-24$

${ }^{b}$ Samples collected on day 28 (ZGN-1061) or day 31 (beloranib).
}

aqueous solution rather than as a suspension. This improved solubility of the ZGN-1061 may in turn be responsible for more rapid systemic bioavailability of ZGN-1061 compared with beloranib after subcutaneous dosing. In nonclinical PK studies, clear differences were apparent between ZGN-1061 and beloranib. Time to peak plasma drug levels and $t_{1 / 2}$ are much shorter, and $C_{\max }$ is much higher for ZGN-1061, while AUC values were similar for the two compounds. ZGN-1061 is also much less extensively bound to plasma proteins than beloranib ( $>95 \%$ for beloranib in all species versus $40 \%-70 \%$ in rat and $\operatorname{dog}$ and $25 \%-35 \%$ in human for ZGN-1061), which may contribute to the more rapid clearance of ZGN-1061 and to differences in tissue distribution and target engagement between the two compounds. PK studies demonstrated that ZGN-1061 was rapidly absorbed and cleared and had a shorter half-life than beloranib in all species tested. The reduced duration of exposure above the $\mathrm{EC}_{50}$ for $\mathrm{EC}$ proliferation with ZGN-1061 is in line with having a minimal risk for adversely affecting venous endothelium and impacting coagulation. These differences were substantiated by a lack of adverse impact on coagulation markers (D-dimer, thrombin time, antithrombin III) and platelet count following repeat administration of ZGN-1061 compared with beloranib in dogs. Finally, in rat toxicology studies, ZGN-1061 was associated with notably reduced toxicity and mortality compared with beloranib.

In conclusion, ZGN-1061 is a potent inhibitor of the MetAP2 enzyme and displays favorable efficacy and safety in preclinical studies. ZGN-1061 produced similar efficacy as beloranib for weight loss, improvements in metabolic parameters in a mouse model of obesity and insulin resistance, and concordant changes in gene transcription in HepG2 cells. However, ZGN-1061 exhibited a markedly better safety profile compared with beloranib. ZGN-1061 did not induce EC proliferation or markers of coagulation in EC cells compared with those observed with beloranib. These effects are likely due to the short action of ZGN-1061 compared with beloranib at the
MetAP2 enzyme, as well as a shorter duration of systemic exposure. Finally, the greater safety of ZGN-1061 compared with beloranib was supported by an improved safety profile in dogs and rats as well as reduced evidence of coagulation in dogs. These findings in ZGN-1061 studies warrant further investigation of the efficacy and safety of ZGN-1061 in humans.

\section{Acknowledgments}

We acknowledge RenaSci for conducting the mouse pharmacology studies; Charles River Laboratories/Argenta Group for conducting the cellular and biochemical studies; Basi for conducting the safety and toxicology investigations; Nextcea and Frank Hsieh for providing mass spectrometry analysis of drug and target engagement; Ocean Ridge Biosciences for conducting Aseq analysis of cell samples; and Sonja K. Billes for providing medical writing support for this manuscript.

\section{Authorship Contributions}

Participated in research design: Burkey, Hoglen, Inskeep, Wyman, Hughes, Vath.

Conducted experiments: Burkey, Hoglen, Inskeep, Wyman.

Performed data analysis: Burkey.

Wrote or contributed to the writing of the manuscript: Burkey, Vath.

\section{References}

Bråkenhielm E, Cao R, Gao B, Angelin B, Cannon B, Parini P, and Cao Y (2004) Angiogenesis inhibitor, TNP-470, prevents diet-induced and genetic obesity in mice. Circ Res 94:1579-1588.

Datta B, Majumdar A, Datta R, and Balusu R (2004) Treatment of cells with the angiogenic inhibitor fumagillin results in increased stability of eukaryotic initiation factor 2-associated glycoprotein, p67, and reduced phosphorylation of extracellular signal-regulated kinases. Biochemistry 43:14821-14831.

Elfers CT and Roth CL (2017) Robust reductions of excess weight and hyperphagia by beloranib in rat models of genetic and hypothalamic obesity. Endocrinology 158 : $41-55$

Foster DA, Yellen P, Xu L, and Saqcena M (2010) Regulation of G1 cell cycle progression: distinguishing the restriction point from a nutrient-sensing cell growth checkpoint(s). Genes Cancer 1:1124-1131.

$\mathrm{Hu}$ W, Lu S, McAlpine I, Jamieson JD, Lee DU, Marroquin LD, Heyen JR, and Jessen BA (2012) Mechanistic investigation of imatinib-induced cardiac toxicity and the involvement of c-Abl kinase. Toxicol Sci 129:188-199.

Hughes TE, Kim DD, Marjason J, Proietto J, Whitehead JP, and Vath JE (2013) Ascending dose-controlled trial of beloranib, a novel obesity treatment for safety, tolerability, and weight loss in obese women. Obesity (Silver Spring) 21:1782-1788. 
Khoh-Reiter S, Sokolowski SA, Jessen B, Evans M, Dalvie D, and Lu S (2015) Contribution of membrane trafficking perturbation to retinal toxicity. Toxicol Sci $\mathbf{1 4 5}$ 383-395.

Kim DD, Krishnarajah J, Lillioja S, de Looze F, Marjason J, Proietto J, Shakib S, Stuckey BG, Vath JE, and Hughes TE (2015) Efficacy and safety of beloranib for weight loss in obese adults: a randomized controlled trial. Diabetes Obes Metab 17: $566-572$.

Kim YM, An JJ, Jin YJ, Rhee Y, Cha BS, Lee HC, and Lim SK (2007) Assessment of the anti-obesity effects of the TNP-470 analog, CKD-732. J Mol Endocrinol 38: $455-465$.

Kumar A, Kim CS, Hoffman TA, Naqvi A, Dericco J, Jung SB, Lin Z, Jain MK, and Irani K (2011) p53 impairs endothelial function by transcriptionally repressing Kruppel-like factor 2. Arterioscler Thromb Vasc Biol 31:133-141.

Kusaka M, Sudo K, Fujita T, Marui S, Itoh F, Ingber D, and Folkman J (1991) Potent anti-angiogenic action of AGM-1470: comparison to the fumagillin parent. Biochem Biophys Res Commun 174:1070-1076.

Lijnen HR, Frederix L, and Van Hoef B (2010) Fumagillin reduces adipose tissue formation in murine models of nutritionally induced obesity. Obesity (Silver Spring) 18:2241-2246.

McCandless SE, Yanovski JA, Miller J, Fu C, Bird LM, Salehi P, Chan CL, Stafford D, Abuzzahab MJ, Viskochil D, et al. (2017) Effects of MetAP2 inhibition on hyperphagia and body weight in Prader-Willi syndrome: a randomized, double-blind, placebo-controlled trial. Diabetes Obes Metab 19:1751-1761.

Proietto J, Arya M, Cohen N, de Looze FJ, Gilfillan P, Hall S, Nathow T, Oldfield GS, O'Neal D, Roberts A, et al. (2016) Weight loss and improvement in glycemic control: results from a 26-week, phase 2, randomized, placebo-controlled, clinical trial of beloranib in patients with obesity and type 2 diabetes. Diabetes 65 (Suppl 1A): LB80.

Schwartz SM (1982) Disturbances in endothelial integrity. Ann N Y Acad Sci 401: $228-233$

Shoemaker A, Proietto J, Abuzzahab MJ, Markovic T, Malloy J, and Kim DD (2017) A randomized, placebo-controlled trial of beloranib for the treatment of hypothalamic injury-associated obesity. Diabetes Obes Metab 19:1165-1170.

Sin N, Meng L, Wang MQ, Wen JJ, Bornmann WG, and Crews CM (1997) The antiangiogenic agent fumagillin covalently binds and inhibits the methionine aminopeptidase, MetAP-2. Proc Natl Acad Sci USA 94:6099-6103.

Warder SE, Tucker LA, McLoughlin SM, Strelitzer TJ, Meuth JL, Zhang Q, Sheppard GS, Richardson PL, Lesniewski R, Davidsen SK, et al. (2008) Discovery, identification, and characterization of candidate pharmacodynamic markers of methionine aminopeptidase-2 inhibition. J Proteome Res 7:4807-4820.

Yau JW, Teoh H, and Verma S (2015) Endothelial cell control of thrombosis. BMC Cardiovasc Disord 15:130.

Zhang Y, Griffith EC, Sage J, Jacks T, and Liu JO (2000) Cell cycle inhibition by the anti-angiogenic agent TNP-470 is mediated by p53 and p21WAF1/CIP1. Proc Natl Acad Sci USA 97:6427-6432.

Address correspondence to: Bryan F. Burkey, Zafgen, Inc., 175 Portland St \#4, Boston, MA 02114. E-mail: bburkey@zafgen.com 